\title{
Utility of the early lactate area score as a prognostic marker for septic shock patients in the emergency department
}

\author{
Gina Yu*, Seung Joon Yoo*, Sang-Hun Lee, June Sung Kim, Sungmin Jung, Youn-Jung Kim, Won Young Kim, \\ Seung Mok Ryoo
}

Department of Emergency Medicine, Asan Medical Center, University of Ulsan College of Medicine, Seoul, Korea

Background: The current Surviving Sepsis Campaign guidelines recommend the remeasurement of lactate levels if the initial lactate level is elevated; however, the prognostic value of lactate kinetics is limited and inconsistent. We attempted to determine the efficacy of the lactate area score (calculated from repeated lactate measurements during initial resuscitation) as a prognostic marker of septic shock in the emergency department (ED).

Methods: We performed a retrospective study of adult patients with septic shock in the ED of a single tertiary medical center. Serial lactate levels were measured five times within 12 hours. We also compared the initial lactate level, maximum lactate level, and lactate area score. The lactate area score was defined as the sum of the area under the curve measured at $2,4,6$, and 12 hours following the initial measurement.

Results: A total of 362 patients were enrolled in this study, and the overall 28-day mortality was $31.8 \%$. The lactate area score of serial lactate levels as well as the initial (median [interquartile range], 4.9 [3.4 to 10.5$] ; P=0.003$ ) and maximum (7.3 [4.2 to 13.2]; $P<0.001$ ) lactate levels were significantly higher in the non-survivor group. However, in multivariate analysis, only the lactate area score (odds ratio, 1.013; 95\% confidence interval, 1.007 to 1.019 ) was significantly associated with 28-day mortality.

Conclusions: The early lactate area score may be a possible prognostic marker for predicting the 28-day mortality of adult septic shock patients. Further prospective interventional studies should be conducted to validate our results.

Key Words: lactic acid; mortality; prognosis; sepsis; shock

\section{INTRODUCTION}

Septic shock remains an important cause of morbidity and mortality among critically ill patients; thus, the Surviving Sepsis Campaign guidelines have been going to consensus for septic shock management [1]. The recent Surviving Sepsis Campaign guidelines recommend 1 hour of bundle therapy, which includes repeated lactate measurements when the initial lactate level is elevated [2]. As an index for tissue hypoxia and accelerated aerobic metabolism, elevated serum lactate is associated with unfavorable outcomes among patients with severe illness [3]. Although elevated serum lactate may not directly reflect tissue hypoxia, it is ac-

\section{Original Article}

Received: August 22, 2018

Revised: October 24, 2018

Accepted: October 25, 2018

\section{Corresponding author}

Seung Mok Ryoo

Department of Emergency Medicine,

Asan Medical Center, University

of Ulsan College of Medicine, 88

Olympic-ro 43-gil, Songpa-gu, Seoul 05505, Korea

Tel: +82-2-3010-3350

Fax: +82-2-3010-3360

E-mail: chrisryoo@amc.seoul.kr

*These authors contributed equally to this article.

Copyright @ 2019 The Korean Society of Critical Care Medicine

This is an Open Access article distributed under the terms of Creative Attributions Non-Commercial License (http:// creativecommons.org/li-censes/by-nc/4.0/) which permits unrestricted noncommercial use, distribution, and reproduction in any medium, provided the original work is properly cited. 
companied by a hypermetabolic state with enhanced glycolysis and hyperlactatemia in cases of severe illness, especially septic shock [3-7]. Serum lactate level is associated with mortality, and hospital mortality has been reported to increase linearly with increasing serum lactate level [8]. Therefore, lactate-guided therapy with repeated measurements has also been recommended in the Surviving Sepsis Campaign [9].

Lactate normalization is a proven prognosis marker among septic shock patients. Since Nguyen et al. [10] reported that over $10 \%$ of lactate clearance reduced mortality by $11 \%$, various studies have demonstrated the prognostic value of lactate clearance [5,11-13]. In the previous studies, not only lactate clearance but also repeated lactate measurements could predict mortality among septic shock patients $[14,15]$. Moreover, other methods of using lactate levels to predict mortality have been investigated [16].

In a recent study of pediatric septic shock patients, the lactate area score, defined as the sum of the area under the curve (AUC) of measured lactate levels, was an independent prognostic factor for mortality with an odds ratio (OR) of 1.143 and 95\% confidence interval (CI) of 1.046-1.250 [17]. However, there have not been enough studies of lactate area score in septic shock [13,17]. In this study, we assessed the lactate area score to predict the 28-day mortality of adult septic shock patients. The objective of this study was to determine the prognostic value of the lactate area score of critically ill patients with septic shock.

\section{MATERIALS AND METHODS}

\section{Setting and Study Population}

This study was a retrospective analysis of a prospective data registry and was performed in the emergency department (ED) of Asan Medical Center with an annual census of more than 100,000 patients in the Republic of Korea. It was approved by the Research Ethics Committee of the Hospital (No. 20151253).

Between January 2010 and December 2017, all adult patients with septic shock who were diagnosed in the ED and treated with protocol-driven resuscitation bundle therapy were enrolled with their data prospectively collected in our institution's Septic Shock Registry. Septic shock was defined as refractory hypotension with a systolic blood pressure of $<90$ mmHg or a mean arterial pressure of $<70 \mathrm{mmHg}$ requiring vasopressors despite adequate fluid resuscitation or a blood lactate concentration of at least $4 \mathrm{mmol} / \mathrm{L}$ [9].

Exclusion criteria were as follows: patients with a "do not

\section{KEY MESSAGES}

- The lactate area score is the sum of the area under the curve of serial lactate levels from repeated measurements using the trapezoidal rule, divided by the time interval.

- The study involved adult septic shock patients in the emergency department, and measurements were performed within 12 hours from shock recognition.

- The lactate area score may be an early prognostic marker of 28-day mortality.

attempt resuscitation" status, patients who were transferred to another hospital during initial resuscitation, and patients who lacked data for repeated lactate measurements. In addition, we excluded patients with missing data of five times on repeated lactate levels.

\section{Data Collection}

Patient demographics and clinical data, including age, sex, past medical history, initial vital signs, laboratory results (such as white blood cell count, prothrombin time, and the levels of hemoglobin, platelet, aspartate transaminase, alanine transaminase, total bilirubin, blood urea nitrogen, creatinine, albu$\mathrm{min}$, and lactate), and disease severity determined by the Sequential Organ Failure Assessment (SOFA) score, were retrieved from the Septic Shock Registry (Table 1).

Lactate levels in arterial blood were measured using a blood gas analyzer (GEM Premier 3,000, display range, 0.3 to 15.0 $\mathrm{mmol} / \mathrm{L}$; Instrumentation Laboratory, Bedford, MA, USA). We measured the lactate level at the time of shock recognition $\left(T_{1}\right)$, which was repeated at $2,4,6$, and 12 hours following the initial measurement $\left(T_{2}, T_{3}, T_{4}, T_{5}\right)$. The lactate area score was defined as the sum of the AUC of serial lactate levels $\left(\mathrm{L}_{1}, \mathrm{~L}_{2}, \mathrm{~L}_{3}\right.$, $\mathrm{L}_{4}, \mathrm{~L}_{5}$ ) measured for 12 hours using the trapezoidal rule, divided by the time interval [17].

$$
\text { Lactate area score }(\mathrm{mmol} / \mathrm{L} \times \mathrm{hr})=\sum_{n=1}^{4}\left(L_{n}+L_{n+1}\right) \frac{1}{2} \times\left(T_{n+1}-T_{n}\right)
$$

The maximum lactate level was the highest level of lactate obtained from serial lactate measurements (five times). The primary clinical outcome of this study was the 28-day mortality rate. We evaluated the predictive ability of each lactate level $\left(\mathrm{L}_{1}, \mathrm{~L}_{2}, \mathrm{~L}_{3}, \mathrm{~L}_{4}, \mathrm{~L}_{5}\right)$, the maximum lactate level, and the lactate area score.

\section{Statistical Analysis}

Continuous variables are presented as the means with differ- 
Table 1. Baseline characteristics of the study population

\begin{tabular}{|c|c|c|c|c|}
\hline Characteristics & All patients $(n=362)$ & Survivor $(n=247)$ & Non-survivor $(n=115)$ & P-value \\
\hline Age (yr) & $64.3 \pm 12.5$ & $64.1 \pm 12.4$ & $64.7 \pm 12.9$ & 0.669 \\
\hline Male sex & $242(66.9)$ & $164(66.4)$ & 78 (67.8) & 0.812 \\
\hline \multicolumn{5}{|l|}{ Past medical history } \\
\hline Hypertension & $108(29.8)$ & $77(31.2)$ & $31(27.0)$ & 0.460 \\
\hline Diabetes & $74(20.4)$ & $48(19.4)$ & $26(22.6)$ & 0.485 \\
\hline Stroke & $25(6.9)$ & $22(8.9)$ & $3(2.6)$ & 0.027 \\
\hline Coronary artery disease & $40(11.0)$ & $27(10.9)$ & $13(11.3)$ & 1.000 \\
\hline Chronic lung disease & $56(15.5)$ & $37(15.0)$ & 19 (16.5) & 0.755 \\
\hline Liver cirrhosis & $52(14.4)$ & $34(13.8)$ & $18(15.7)$ & 0.371 \\
\hline \multicolumn{5}{|l|}{ Vital sign } \\
\hline Systolic blood pressure $(\mathrm{mmHg})$ & $106.5 \pm 31.6$ & $106.1 \pm 30.8$ & $107.4 \pm 33.4$ & 0.705 \\
\hline Diastolic blood pressure $(\mathrm{mmHg})$ & $65.7 \pm 22.0$ & $65.6 \pm 51.6$ & $65.9 \pm 23.2$ & 0.931 \\
\hline Respiratory rate (rates/min) & $22.0(20.0-30.6)$ & $21.0(20.0-28.0)$ & $22.0(20.0-26.0)$ & 0.195 \\
\hline Pulse rate (beats/min) & $105.1 \pm 31.6$ & $103.8 \pm 30.3$ & $108.0 \pm 34.2$ & 0.101 \\
\hline Body temperature $\left({ }^{\circ} \mathrm{C}\right)$ & $37.5 \pm 1.4$ & $37.5 \pm 1.4$ & $37.5 \pm 1.3$ & 0.125 \\
\hline \multicolumn{5}{|l|}{ Severity } \\
\hline SOFA score & $11.0(8.0-14.8)$ & $10.0(8.0-13.0)$ & $13.0(11.0-16.0)$ & $<0.001$ \\
\hline Lactate area score & $43.7(26.4-71.4)$ & $38.8(22.7-58.0)$ & $57.0(33.9-98.0)$ & $<0.001$ \\
\hline \multicolumn{5}{|l|}{ Presumed site of infection } \\
\hline Respiratory tract & 155 (42.8) & 98 (39.7) & $57(49.6)$ & 0.077 \\
\hline Urinary tract & $22(6.1)$ & $20(8.1)$ & $2(1.7)$ & 0.018 \\
\hline Gastrointestinal tract & $40(11.0)$ & 27 (10.9) & 13 (11.3) & 0.916 \\
\hline Hepato-biliary tract & $82(22.7)$ & $63(25.5)$ & 19 (16.5) & 0.057 \\
\hline Bone or soft tissue & $16(4.4)$ & $9(3.6)$ & $7(6.1)$ & 0.292 \\
\hline Other & $44(12.2)$ & $28(11.3)$ & 16 (13.9) & 0.485 \\
\hline
\end{tabular}

Values are presented as mean \pm standard deviation, number (\%), or median (interquartile range).

SOFA: Sequential Organ Failure Assessment.

ences or medians with interquartile ranges, which were compared between patients by independent t-test and MannWhitney test. Categorical variables are summarized as frequencies and percentages, and differences between two groups were analyzed by Fisher's exact test.

To evaluate the relationship between mortality and lactate variables, univariate and multivariate logistic regression analyses with backward elimination were performed. We presented the OR with $95 \%$ CI for each model. The factors associated with mortality such as past history of stroke, infection site of urinary tract, laboratory tests of platelet, prothrombin time, albumin, blood urea nitrogen, creatinine, C-reactive protein, initial lactate, maximum lactate, severity factors of lactate and lactate area score were included in a multivariate logistic regression model. The model performance was evaluated using the receiver operating characteristic (ROC) curve with the
AUC of each ROC curve. We considered $\mathrm{P}<0.05$ as statistically significant for all of the analyses.

\section{RESULTS}

\section{Baseline Characteristics of the Study Population}

A total of 362 adult patients were enrolled in this study, and their 28-day mortality was $31.8 \%$ (Figure 1 ). When we divided patients into the survivor and non-survivor group, age, sex, initial vital signs, and past medical history were not significantly different except for stroke, which was more frequent in the survivor group ( $88.0 \%$ vs. $12.0 \%, \mathrm{P}=0.027$ ). However, the SOFA score (median [interquartile range], 10.0 [8.0 to 13.0] vs. 13.0 [11.0 to 16.0]; $\mathrm{P}<0.001)$ and lactate area score (38.8 [22.7 to 58.0] vs. 57.0 [33.9 to 98.0]; $\mathrm{P}<0.001$ ) were significantly higher in the non-survivor group, whereas urinary tract infection 


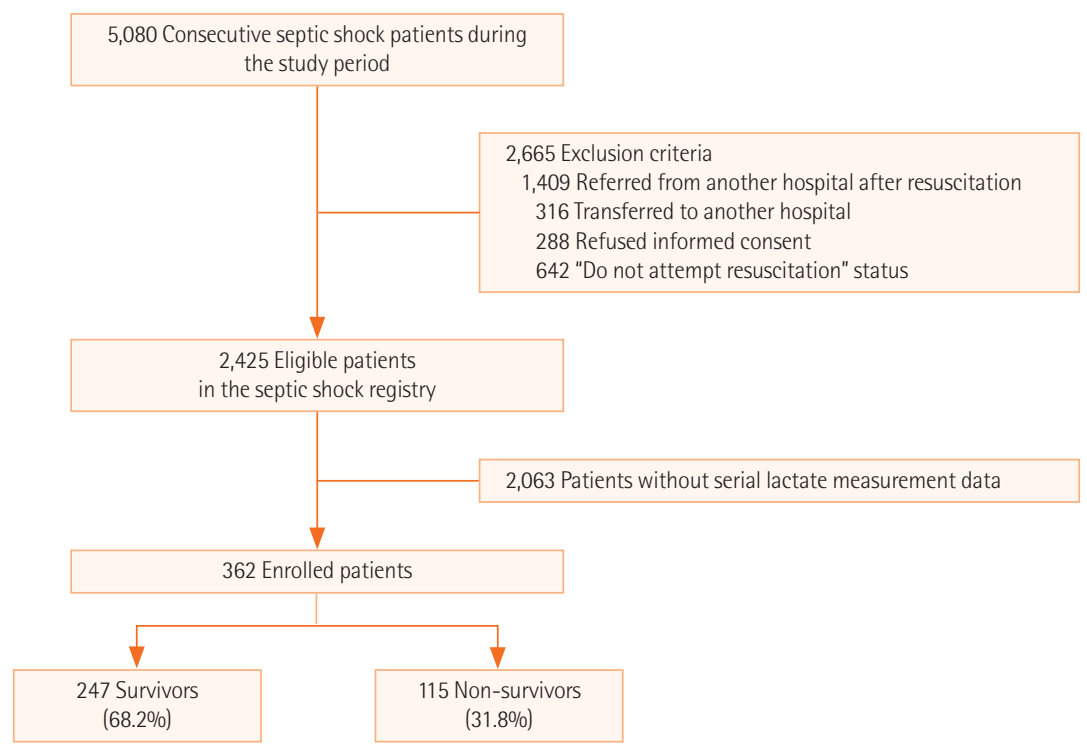

Figure 1. Flowchart of the selection and classification of patients.

Table 2. Laboratory findings of survivors and non-survivors

\begin{tabular}{lccc}
\hline Characteristics & Survivor $(\mathrm{n}=247)$ & Non-survivor $(\mathrm{n}=115)$ & P-value \\
\hline White blood cell $\left(\times 10^{3} / \mu \mathrm{l}\right)$ & $11.6(4.9-19.1)$ & $11.3 \pm 2.7$ & 0.688 \\
Hemoglobin $(\mathrm{g} / \mathrm{dl})$ & $11.6 \pm 2.8$ & $140.5(49.0-186.3)$ & 0.393 \\
Platelet $\left(\times 10^{3} / \mathrm{\mu l}\right)$ & $183.5(94.0-268.3)$ & $46.0(27.0-197.5)$ & 0.049 \\
Aspartate transaminase $(\mathrm{IU} / \mathrm{L})$ & $44.0(28.0-74.3)$ & $33.5(14.0-69.3)$ & 0.664 \\
Alanine transaminase $(\mathrm{IU} / \mathrm{L})$ & $25.0(14.8-46.3)$ & $1.3(0.7-3.2)$ & 0.842 \\
Total bilirubin $(\mathrm{mg} / \mathrm{dl})$ & $1.0(0.6-2.3)$ & $1.4(1.2-2.0)$ & 0.435 \\
Prothrombin time $(\mathrm{INR})$ & $1.3(1.1-1.6)$ & $2.5 \pm 0.6$ & 0.001 \\
Albumin $(\mathrm{mg} / \mathrm{dl})$ & $2.8 \pm 0.7$ & $30.5(18.8-47.0)$ & $<0.001$ \\
Blood urea nitrogen $(\mathrm{mg} / \mathrm{dl})$ & $27.5(17.0-41.3)$ & $1.6(1.1-2.3)$ & 0.042 \\
Creatinine $(\mathrm{mg} / \mathrm{dl})$ & $1.4(1.0-2.6)$ & $15.8(7.4-24.0)$ & 0.004 \\
C-reactive protein $(\mathrm{mg} / \mathrm{dl})$ & $8.1(3.0-20.5)$ & $4.9(3.4-10.5)$ & 0.009 \\
Initial lactate $(\mathrm{mmol} / \mathrm{L})$ & $4.2(2.4-6.6)$ & $4.7(2.3-7.5)$ & 0.003 \\
2-Hour lactate $(\mathrm{mmol} / \mathrm{L})$ & $3.3(1.9-5.4)$ & $4.2(2.2-8.2)$ & 0.001 \\
4-Hour lactate $(\mathrm{mmol} / \mathrm{L})$ & $2.8(1.7-4.7)$ & $4.5(2.3-8.1)$ & $<0.001$ \\
6-Hour lactate $(\mathrm{mmol} / \mathrm{L})$ & $2.7(1.6-4.5)$ & $4.6(2.6-9.9)$ & $<0.001$ \\
12-Hour lactate $(\mathrm{mmol} / \mathrm{L})$ & $2.6(1.6-4.8)$ & $7.3(4.2-13.2)$ & $<0.001$ \\
Maximum lactate $(\mathrm{mmol} / \mathrm{L})$ & $5.4(3.2-8.1)$ & $<0.001$ & \\
\hline
\end{tabular}

Values are presented as median (interquartile range) or mean \pm standard deviation.

INR: international normalized ratio.

was significantly frequent in survivor group (8.1\% vs. $1.7 \%$, $\mathrm{P}=0.018$ ) (Table 1).

\section{Laboratory Findings of Survivors and Non-survivors}

In the non-survivor group, the platelet count was lower (183.5 vs. $\left.140.5 \times 10^{3} / \mu \mathrm{l}, \mathrm{P}=0.049\right)$, prothrombin time was longer $(1.3$ vs. 1.4, $\mathrm{P}=0.001$ ), and albumin level was lower (2.8 vs. $2.5 \mathrm{mg}$ / $\mathrm{dl}, \mathrm{P}<0.001)$; however, the levels of blood urea nitrogen $(27.5$ vs. $30.5 \mathrm{mg} / \mathrm{dl}, \mathrm{P}=0.042$ ), creatinine ( 1.4 vs. $1.6 \mathrm{mg} / \mathrm{dl}, \mathrm{P}=0.004$ ), and C-reactive protein ( 8.1 vs. $15.8 \mathrm{mg} / \mathrm{dl}, \mathrm{P}=0.009$ ) were higher. All serial lactate levels and the maximum lactate level were significantly higher in the non-survivor group (4.2 vs. $4.9,3.3$ 
Table 3. Multivariate analysis for predicting 28-day mortality

\begin{tabular}{|c|c|c|c|}
\hline Characteristics & Univariate OR (95\% Cl) & Multivariate OR (95\% Cl) & P-value \\
\hline Stroke & $0.274(0.080-0.935)$ & & \\
\hline Urinary tract infection & $0.201(0.046-0.875)$ & & \\
\hline Platelet $\left(\times 10^{3} / \mu \mathrm{l}\right)$ & 0.999 (0.997-1.001) & & \\
\hline Prothrombin time (INR) & 1.141 (0.979-1.330) & & \\
\hline Albumin (mg/dl) & $0.489(0.347-0.690)$ & $0.586(0.407-0.843)$ & 0.004 \\
\hline Blood urea nitrogen (mg/dl) & 1.007 (0.998-1.016) & & \\
\hline Creatinine (mg/dl) & $1.136(1.001-1.289)$ & & \\
\hline C-reactive protein (mg/dl) & $1.023(1.003-1.042)$ & & \\
\hline Initial lactate (mmol/L) & $1.100(1.038-1.165)$ & & \\
\hline Maximum lactate $(\mathrm{mmol} / \mathrm{L})$ & $1.143(1.081-1.209)$ & & \\
\hline SOFA score & 1.126 (1.060-1.197) & $1.082(1.014-1.153)$ & 0.017 \\
\hline Lactate area score $(\mathrm{mmol} / \mathrm{L} \times \mathrm{hr})$ & $1.016(1.010-1.022)$ & $1.013(1.007-1.019)$ & $<0.001$ \\
\hline
\end{tabular}

Multivariate analysis included logistic regression analysis and backward elimination.

OR: odds ratio; Cl: confidence interval; INR: international normalized ratio; SOFA: Sequential Organ Failure Assessment.

Table 4. Comparison of the AUC between the initial lactate, maximum lactate, and lactate area score

\begin{tabular}{lccc}
\hline Variable & AUC & $95 \% \mathrm{Cl}$ & P-value \\
\hline Initial lactate $(\mathrm{mmol} / \mathrm{L})$ & 0.596 & $0.532-0.659$ & 0.003 \\
Maximum lactate $(\mathrm{mmol} / \mathrm{L})$ & 0.635 & $0.572-0.698$ & $<0.001$ \\
Lactate area score $(\mathrm{mmol} / \mathrm{L} \times \mathrm{hr})$ & 0.659 & $0.597-0.720$ & $<0.001$ \\
\hline
\end{tabular}

AUC: area under the curve; $\mathrm{Cl}$ : confidence interval.

vs. $4.7,2.8$ vs. $4.2,2.7$ vs. $4.5,2.6$ vs. 4.6 , and 5.4 vs. $7.3 \mathrm{mmol} / \mathrm{L}$ with $\mathrm{P}=0.003, \mathrm{P}=0.001, \mathrm{P}<0.001, \mathrm{P}<0.001, \mathrm{P}<0.001$, and $\mathrm{P}<$ 0.001 , respectively) (Table 2 ).

\section{Predicting 28-Day Mortality}

We analyzed disease severity using a logistic regression model, which revealed that the SOFA score and lactate area score were highly associated with 28-day mortality (OR, 1.126; 95\% CI, 1.060 to 1.197 and OR, 1.016; 95\% CI, 1.010 to 1.022 , respectively). In multivariate analysis, the lactate area score (OR, 1.013; 95\% CI, 1.007 to 1.019 ), serum albumin (OR, 0.586; 95\% CI, 0.407 to 0.843 ), and SOFA score (OR, $1.082 ; 95 \% \mathrm{CI}, 1.014$ to 1.153) were significantly associated with mortality (Table 3).

A comparison of the AUC of the ROC curve between the initial lactate, maximum lactate, and lactate area score revealed that the lactate area score was higher (AUC [95\% CI]: 0.596 [0.532 to 0.659 ], 0.635 [0.572 to 0.698], and 0.659 [0.597 to 0.720], respectively) (Table 4, Figure 2). However, the difference between the maximum lactate and lactate area score was not statistically significant $(\mathrm{P}=0.071)$.

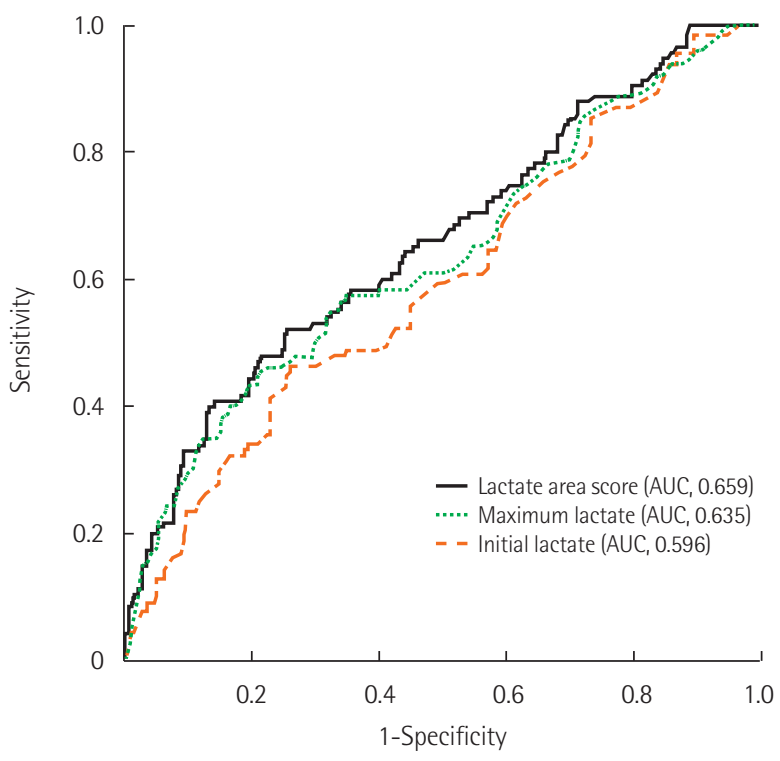

Figure 2. Receiver operating characteristic and area under the curve $(A \cup C)$ in lactate area score, maximum lactate, and initial lactate.

\section{DISCUSSION}

In this study, we found that the lactate area score obtained from serial lactate measurements was independently associated with 28-day mortality among septic shock patients in the ED. However, the OR of the lactate area score for predicting mortality was not only lower than that in previous studies, which involved pediatric septic shock patients, but also lower than the SOFA score. 
Although the initial lactate level is a biomarker that can be used to determine the prognosis and severity of septic shock [18], it represents only the initial status and cannot reflect the effect of initial resuscitation. As serial lactate measurements reflect the response to the initial management, they may be a suitable predictor. In this study, the initial lactate level as well as $\mathrm{L}_{2}, \mathrm{~L}_{3}, \mathrm{~L}_{4}$, and $\mathrm{L}_{5}$ were associated with mortality (Table 2). However, the discrepancy in the median values between survivors and non-survivors was increased with time $\left(\mathrm{T}_{1}, 0.7 \mathrm{mmol} / \mathrm{L}\right.$; $\mathrm{T}_{2}, 1.4 \mathrm{mmol} / \mathrm{L} ; \mathrm{T}_{3}, 1.4 \mathrm{mmol} / \mathrm{L} ; \mathrm{T}_{4}, 1.8 \mathrm{mmol} / \mathrm{L}$; and $\mathrm{T}_{5}, 2.0 \mathrm{mmol} /$ $\mathrm{L}$ ). This result indicated that the prognostic value of lactate levels may increase with time. Our previous study showed that the optimal timing of lactate remeasurements for predicting mortality was 6 hours from shock development [15].

In studies by Kim et al. [17] and Wang et al. [13], the use of the lactate area score as a predictor of mortality has been proposed. In contrast to the initial lactate level, the exposure time to ischemia was considered by quantifying the accumulations of lactate at each time. In both studies, serial lactate measurements were performed in the early phase of septic shock for 24 hours every 6 hours from ICU admission, and the lactate area score was calculated using the trapezoidal rule. They demonstrated that the score was significantly associated with mortality. However, considering lactate kinetics, repeated lactate measurements for 24 hours might be too long to accurately reflect early mortality among septic shock patients [12,19-21]. In this study, we measured lactate levels for 12 hours (every 2 hours in the initial 6 hours) to give a more precise prognosis. The lactate area score was an independent predictor of mortality among adult septic shock patients (OR, 1.013; 95\% CI, 1.007 to 1.019) in multivariate analysis. In the AUC of the ROC curve, the lactate area score was higher than the initial and maximum lactate levels. Although this result was similar to that of previous studies, the AUC value was lower, and the difference from the maximum lactate level was not statistically significant $[13,17]$. Unlike previous studies, our study was conducted in the very early phase of septic shock in the ED and not the ICU. In addition, we measured lactate levels more frequently (five times) within 12 hours. The association might be decreased because initial resuscitation includes hemodynamic stabilization, and early antibiotic administration is crucial for reducing mortality $[2,22]$. Although the lactate area score may be an independent predictor, its statistical relevance is limited.

There are several limitations in our study. First, it was a retrospective observational study in a single medical center. $\mathrm{Al}$ though a large number of patients were included, many pa- tients with missing data on serial lactate levels were excluded. Multiple measurements of lactate levels might include patients with more severe illness, and it can dilute the results of lactate area score assessment due to severe illness in the comparisons. Since the same reason, AUC of lactate area score might lower than other studies. The overall 28-day mortality was higher than that of other similarly designed studies involving patients with septic shock $(26.2 \%-36 \%)[17,23,24]$. One more important limitation was that the calculation method is not easy.

Despite these limitations, the early lactate area score may be an possible prognostic marker for predicting the 28-day mortality of adult septic shock patients. To generalize our results, further prospective multicenter interventional studies should be conducted to validate our results.

\section{CONFLICT OF INTEREST}

No potential conflict of interest relevant to this article was reported.

\section{ACKNOWLEDGMENTS}

We thank Min-Ju Kim (Department of Medical Statistics, Asan Medical Center, Seoul, Korea) for help with statistical analysis.

\section{ORCID}

Gina Yu

Seung Joon Yoo

https://orcid.org/0000-0002-7484-405X

Sang-Hun Lee

https://orcid.org/0000-0001-7774-1374

June Sung Kim

Sungmin Jung

https://orcid.org/0000-0003-4303-7375

Youn-Jung Kim

https://orcid.org/0000-0002-9941-585X

https://orcid.org/0000-0002-6992-7088

Won Young Kim

https://orcid.org/0000-0003-1385-5836

Seung Mok Ryoo

https://orcid.org/0000-0002-6904-5966

https://orcid.org/0000-0002-2436-3311

\section{AUTHOR CONTRIBUTIONS}

Conceptualization: SMR. Data curation: SJ. Formal analysis: GY, YJK. Funding acquisition: SMR. Methodology: SJY. Project administration: SHL. Visualization: JSK. Writing - original draft: GY. Writing - review \& editing: SMR, WYK.

\section{REFERENCES}

1. Shankar-Hari M, Phillips GS, Levy ML, Seymour CW, Liu VX, 
Deutschman CS, et al. Developing a new definition and assessing new clinical criteria for septic shock: for the third international consensus definitions for Sepsis and Septic Shock (Sepsis-3). JAMA 2016;315:775-87.

2. Levy MM, Evans LE, Rhodes A. The surviving sepsis campaign bundle: 2018 update. Crit Care Med 2018;46:997-1000.

3. Jansen TC, van Bommel J, Bakker J. Blood lactate monitoring in critically ill patients: a systematic health technology assessment. Crit Care Med 2009;37:2827-39.

4. Jansen TC, van Bommel J, Mulder PG, Rommes JH, Schieveld SJ, Bakker J. The prognostic value of blood lactate levels relative to that of vital signs in the pre-hospital setting: a pilot study. Crit Care 2008;12:R160.

5. Jansen TC, van Bommel J, Woodward R, Mulder PG, Bakker J. Association between blood lactate levels, Sequential Organ Failure Assessment subscores, and 28-day mortality during early and late intensive care unit stay: a retrospective observational study. Crit Care Med 2009;37:2369-74.

6. Suetrong B, Walley KR. Lactic acidosis in sepsis: it's not all anaerobic: implications for diagnosis and management. Chest 2016;149:252-61.

7. Ryoo SM, Kim WY. Clinical applications of lactate testing in patients with sepsis and septic shock. J Emerg Crit Care Med 2018;2:14.

8. Singer M, Deutschman CS, Seymour CW, Shankar-Hari M, Annane D, Bauer M, et al. The third international consensus definitions for Sepsis and Septic Shock (Sepsis-3). JAMA 2016; 315:801-10.

9. Rhodes A, Evans LE, Alhazzani W, Levy MM, Antonelli M, Ferrer R, et al. Surviving sepsis campaign: international guidelines for management of sepsis and septic shock: 2016. Intensive Care Med 2017;43:304-77.

10. Nguyen HB, Rivers EP, Knoblich BP, Jacobsen G, Muzzin A, Ressler JA, et al. Early lactate clearance is associated with improved outcome in severe sepsis and septic shock. Crit Care Med 2004;32:1637-42.

11. Scott HF, Brou L, Deakyne SJ, Fairclough DL, Kempe A, Bajaj L. Lactate clearance and normalization and prolonged organ dysfunction in pediatric sepsis. J Pediatr 2016;170:149-55.e1-4.

12. Sterling SA, Puskarich MA, Jones AE. The effect of liver disease on lactate normalization in severe sepsis and septic shock: a cohort study. Clin Exp Emerg Med 2015;2:197-202.

13. Wang H, Li Z, Yin M, Chen XM, Ding SF, Li C, et al. Combination of Acute Physiology and Chronic Health Evaluation II score, early lactate area, and $\mathrm{N}$-terminal prohormone of brain natriuretic peptide levels as a predictor of mortality in geriat- ric patients with septic shock. J Crit Care 2015;30:304-9.

14. Ryoo SM, Lee J, Lee YS, Lee JH, Lim KS, Huh JW, et al. Lactate level versus lactate clearance for predicting mortality in patients with septic shock defined by Sepsis-3. Crit Care Med 2018;46:e489-95.

15. Ryoo SM, Ahn R, Lee J, Sohn CH, Seo DW, Huh JW, et al. Timing of repeated lactate measurement in patients with septic shock at the emergency department. Am J Med Sci 2018;356: 97-102.

16. Shin J, Hwang SY, Jo IJ, Kim WY, Ryoo SM, Kang GH, et al. Prognostic value of the lactate/albumin ratio for predicting 28-day mortality in critically ill sepsis patients. Shock 2018;50:545-50.

17. Kim YA, Ha EJ, Jhang WK, Park SJ. Early blood lactate area as a prognostic marker in pediatric septic shock. Intensive Care Med 2013;39:1818-23.

18. Casserly B, Phillips GS, Schorr C, Dellinger RP, Townsend SR, Osborn TM, et al. Lactate measurements in sepsis-induced tissue hypoperfusion: results from the Surviving Sepsis Campaign database. Crit Care Med 2015;43:567-73.

19. Arnold RC, Shapiro NI, Jones AE, Schorr C, Pope J, Casner E, et al. Multicenter study of early lactate clearance as a determinant of survival in patients with presumed sepsis. Shock 2009;32:35-9.

20. Bolvardi E, Malmir J, Reihani H, Hashemian AM, Bahramian $\mathrm{M}$, Khademhosseini $\mathrm{P}$, et al. The role of lactate clearance as a predictor of organ dysfunction and Mortality in patients with severe sepsis. Mater Sociomed 2016;28:57-60.

21. Lokhandwala S, Andersen LW, Nair S, Patel P, Cocchi MN, Donnino MW. Absolute lactate value vs relative reduction as a predictor of mortality in severe sepsis and septic shock. J Crit Care 2017;37:179-84.

22. Ryoo SM, Kim WY, Sohn CH, Seo DW, Koh JW, Oh BJ, et al. Prognostic value of timing of antibiotic administration in patients with septic shock treated with early quantitative resuscitation. Am J Med Sci 2015;349:328-33.

23. Ilias I, Apollonatou S, Vassiliadi DA, Nikitas N, Theodorakopoulou M, Diamantakis A, et al. Adipose tissue lactate clearance but not blood lactate clearance is associated with clinical outcome in sepsis or septic shock during the post-resuscitation period. Metabolites 2018;8:E28.

24. Driessen RG, van de Poll MC, Mol MF, van Mook WN, Schnabel RM. The influence of a change in septic shock definitions on intensive care epidemiology and outcome: comparison of sepsis-2 and sepsis-3 definitions. Infect Dis (Lond) 2018;50: 207-13. 